\title{
On the slippage of deep-drogued drifters
}

\author{
W. Krauss \\ Institut für Meereskunde, Universitát Kiel, Kiel, Germany
}

\begin{abstract}
Deep-drogued drifters are in use to measure the near-surface geostrophic currents. An attempt is made to study the slippage of these drifters due to wind and Ekman currents. The results are based on a data set from the unstratified North Sea obtained in winter 1991-1992, where the currents were decomposed into Ekman currents and barotropic currents. The influence of these Ekman currents on the drift performance of drifters drogued below the mixed layer in the barotropic current is determined by using quadratic drag laws. In $90 \%$ of all cases (1540 data points) the combined effect of wind drag and Ekman currents on buoy and 100-m tether produces a slippage of less than 2 $\mathrm{cm} / \mathrm{s}$. Drifters drogued within the mixed layer show less slippage due to the reduced drag on the tether, but they are primarily designed to measure the actual near-surface currents, which are strongly dependent on the wind conditions. It is concluded that deep-drogued drifters are a reliable device to study weakly baroclinic geostrophic currents.
\end{abstract}

\section{Introduction}

Considerable progress has been made during the last decades in describing and understanding the current system of the upper ocean. Numerical models, Lagrangian drifters, and altimeter data begin to fill the gaps which were left by the classical method of hydrographic surveys and the uncertainties in the reference level. However, in order to describe the actual near-surface current systems by measurements, data sets would be required with much higher spatial and temporal resolution than is presently available. In the North Atlantic north of the Subtropics, for example, most major currents are associated with thermohaline fronts. Their width is typically of $O(100$ $\mathrm{km}$ ). Eddies have similar scales, decreasing toward higher latitudes [Krauss et al., 1990b; Stammer and Böning, 1992].

The existing data sets are far from being able to describe these scales:

1. Hydrographic sections, especially at high latitudes, do not sufficiently resolve the eddy scale and are generally separated from one another by hundreds of kilometers.

2. Altimeter data of sea surface displacement do provide high resolution along tracks but provide no information between the tracks.

3. Lagrangian drifters, even if used in large numbers, do not provide homogeneous coverage of an area in space and time.

Only eddy-resolving numerical models are potentially able to produce a complete ocean state. These models, however, still have many deficiencies, especially at high latitudes. However, with increasing horizontal resolution the results from models, altimeters, and drifters begin to merge [Beckmann et al., 1994].

One of the weakest points in these models at present is the description of the mixed surface layer. Most models include simple Ekman dynamics with an arbitrary eddy viscosity. Experiments in the stratified subtropical ocean [Price et al., 1986, 1987] have shown that even a rather small stratification due to the upper ocean's diurnal cycle can strongly reduce the depth

Copyright 1996 by the American Geophysical Union.

Paper number $95 \mathrm{JC} 02686$.

0148-0227/96/95JC-02686\$05.00 of the Ekman layer and can thus lead to surface-trapped current profiles. These currents in a stratified surface layer are entirely different from those in homogeneous water [Krauss, 1993]. The rather simple dynamics of the Ekman layer in ocean models makes it difficult to compare or combine model currents with observed ones near the surface. Contrary to that below the mixed layer, geostrophy is the dominant balance in all permanent ocean currents, transient eddies, and meanders. Therefore comparison of model results with observations or assimilation of data into the models requires data which are representative for geostrophic flow fields. In this article we shall discuss whether deep-drogued, satellite-tracked buoys give reliable information about these fields.

Most drifters have been deployed with drogues at less than $30-\mathrm{m}$ depth in the mixed layer. Depending on area and time, their drift results from the superposition of quasi-geostrophic and Ekman currents. McNally [1981] has shown for the northeastern North Pacific that monthly averaged drifter vectors in the mixed layer followed the monthly mean isobars of the air pressure field. In the area $40^{\circ}-45^{\circ} \mathrm{N}, 130^{\circ}-150^{\circ} \mathrm{W}$, for example, the flow in February 1977 was toward northeast, whereas in the following month the flow was toward southeast owing to a different air pressure pattern. The effectiveness of the drogues in this case has been questioned [Davis, 1991], but also Emery et al. [1985], on the basis of mixed layer drifters, obtained a high correlation between mean monthly drift directions and geostrophic wind direction but no correlation between mean monthly drift direction and geostrophic currents derived from monthly mean dynamic heights $(0 / 200 \mathrm{dbar})$. The strong influence of Ekman currents on mixed layer drifters can also be seen in the tropical Pacific, where the buoys systematically drift away from the equator [Hansen and Paul, 1987] because of Ekman divergence.

To avoid the influence of varying meteorological conditions, typical for middle and high latitudes, deep-drogued drifters are used more and more. Gyre-scale experiments with drifters drogued at $120 \mathrm{~m}$ have been performed by Thomson et al. [1990] in the northeastern Pacific. In the North and South Atlantic, buoys deployed by the Institut für Meereskunde (IfM), Kiel, Germany [Brügge, 1995; Schäfer and Krauss, 1995], are generally drogued at $100 \mathrm{~m}$. Local experiments with deep- 
drogued drifters have been conducted by Colin de Verdière [1983] and Booth [1988].

The IfM data set for the North Atlantic is based on 199 Hermes buoys deployed during 1981-1989. A similar large data set will be gained for the South Atlantic by an ongoing experiment during which more than 200 buoys of Atlantic Oceanographic and Meteorological Laboratory (AOML) type [Bitterman and Hansen, 1986] will be deployed.

Little is known about the drift performance of buoys under severe wind conditions. Under stationary conditions the sum of the forces $\mathbf{K}_{l}$ acting on the different components of the system must balance each other:

$$
\sum_{\imath} \mathbf{K}_{l}=0
$$

where $\mathbf{K}$ is generally supposed to follow a quadratic drag law [e.g., Geyer, 1989] of the form

$$
\mathbf{K}=\rho c A|\mathbf{v}| \mathbf{v} / 2 .
$$

Here $\rho$ is the density of the surrounding fluid; $A$ is the cross area, which is exposed to the flow; $\mathbf{v}$ is the relative velocity; and $c$ is a drag coefficient. These forces are (1) wind drag on the buoy above sea level, (2) current drag on the submerged part of the buoy, (3) drag of currents on the tether between sea surface and drogue, and (4) drag on the drogue, if the drogue does not move exactly with the speed of the surrounding water owing to forces $1-3$. The main balance of forces is generally between force 2 and 4 ; in order to minimize the slippage the ratio $K_{B} / K_{D}$ has to be small. Here the indices $B$ and $D$ refer to buoy and drogue in (2). For deep-drogued buoys the drag on the tether in the Ekman layer can become an additional source of slippage. It is therefore generally believed that deepdrogued drifters are less reliable to give the correct current speed. This belief, however, is not substantiated by measurements. Many additional factors influencing the system are unknown yet:

1. The validity range for the quadratic law is not defined.

2 . Stokes drift and wave action on the buoy system, especially under high winds, are not explored.

3. Shear within the mixed layer may influence the system much more strongly if the drogue is within the mixed layer than if it is well below.

Many attempts have been made to calibrate drifters under real conditions, but none of them was satisfactory. A calibration would require measuring slippage under all wind conditions, which has not been possible for any of the existing drifters.

Niiler et al. [1987] tested their buoy configuration in winds of $2-10 \mathrm{~m} / \mathrm{s}$. Geyer [1989] performed two experiments: the wind was $4-6 \mathrm{~m} / \mathrm{s}$ during the first one and $10-12 \mathrm{~m} / \mathrm{s}$ during the second. World Ocean Circulation Experiment drifters are generally said to be "calibrated," but calibrations have been conducted only under light winds of 7-10 m/s [Bitterman et al., 1990]. Krauss et al. [1989] have shown that the forces on the Hermes buoy can be described by a quadratic law (equation (2)) for drift velocities up to $70 \mathrm{~cm} / \mathrm{s}$.

The general result of these measurements in the mixed layer is that slippage under the conditions given above is typically $1-2 \mathrm{~cm} / \mathrm{s}$. Deep-drogued drifters may have a slightly higher slippage due to the drag on the tether within the Ekman layer. For drifters drogued at $100 \mathrm{~m}$, Colin de Verdière [1983] estimated that the drifters follow the water motion with a rms precision of typically $15 \%$. Booth [1988] estimated a slippage of $<1.3 \mathrm{~cm} / \mathrm{s}$ for $10-\mathrm{m} / \mathrm{s}$ wind, and Krauss et al. [1990a] showed that during the passage of a storm the drift speed increased by $1.7 \mathrm{~cm} / \mathrm{s}$ per $10-\mathrm{m} / \mathrm{s}$ increase in wind speed. Willebrand et al. [1990], in comparing geostrophic velocities in the Gulf Stream extension area as derived from altimeter data with drifters drogued at $100 \mathrm{~m}$, obtained a relation $v_{\mathrm{Alt}}=1.04( \pm 0.6)+$ $0.93( \pm 0.04) v_{\text {Drift }}$, which gives slightly lower velocities for the altimeter data.

In summary, a real calibration does not exist for any drifter under all wind conditions. On the other hand, satellite-tracked buoys are the only devices that allow a direct oceanwide description of near-surface currents. Altimeter data may become superior during the next decades.

In the subsequent sections we try to estimate how deepdrogued drifters are influenced by the Ekman layer. As was outlined above, drifters in the mixed layer are driven by both the geostrophic currents and the time-variable Ekman currents. In middle and high latitudes, these two contributions cannot be separated in a stratified ocean, where eddies play a dominant role. In order to assess the quality of drifters drogued below the mixed layer we compute the influence of Ekman currents on the system, assuming that the quadratic law holds. The analysis is based on a data set which has been obtained in winter 1991-1992 in the central North Sea. During this time this area is homogeneous, allowing only Ekman currents and barotropic currents. The separation of both for a 4-week period was described in detail by Krauss [1993]. We now use the remaining 2 months of these data to evaluate the drift behavior of deep-drogued drifters. We believe that the results can be applied to the deep ocean in the northern North Atlantic at least during winter conditions, because the upper layer in the North Atlantic during winter is homogeneous as in the North Sea, and the baroclinic currents in the upper $100 \mathrm{~m}$ vary little with depth because the first baroclinic mode generally dominates the vertical current structure.

The outline of this paper is as follows. In section 2 we describe the data set and the decomposition of the drift velocities into barotropic and Ekman components. The influence of Ekman currents on deep-drogued drifters is computed in section 3. Similarly, in section 4 we compute the slippage of drifters drogued in the mixed layer. In both cases, quadratic laws are assumed to hold. In section 5 we conclude that deepdrogued drifters are a reliable device to study geostrophic currents, which are approximately depth independent within the upper $100 \mathrm{~m}$.

\section{Data Set and Analysis}

Five satellite-tracked buoys at five different levels, deployed on November 20,1991 , at $57^{\circ} \mathrm{N}, 2^{\circ} \mathrm{E}$, in the central North Sea are used in this study. The buoys have been designed according to the specifications of AOML [Bttterman and Hansen, 1986] and have been widely used in the Tropical Ocean-Global Atmosphere program. They are presently used in the South Atlantic by IfM Kiel. The system consists of a spar buoy, which is a cylindrical tube $2.60 \mathrm{~m}$ in length and $11 \mathrm{~cm}$ in diameter. The upper $60 \mathrm{~cm}$ are (theoretically) exposed to the wind; however, this part is often submerged in rough sea. The cross areas of the buoy are $0.066 \mathrm{~m}^{2}$ in air and $0.22 \mathrm{~m}^{2}$ in water. A tether 100 $m$ in length and $1.1 \mathrm{~cm}$ in diameter, yielding a cross area of 1.10 $\mathrm{m}^{2}$, connects the drogue with the buoy. The drogue is a holey sock of $10-\mathrm{m}$ length and $1-\mathrm{m}$ diameter, which gives a cross area 
of $10 \mathrm{~m}^{2}$. The drogues of these five buoys covered the ranges 3-13 m, 7-17 m, 12-22 m, 17-27 m, and 22-32 m.

For the interpretation of the results the data were attached to nominal depths of $7.5 \mathrm{~m}, 12.5 \mathrm{~m}, 17.5 \mathrm{~m}, 22.5 \mathrm{~m}$, and $27.5 \mathrm{~m}$ (center of the drogue). The location of deployment is shown by the circle in Figure 1. The shaded area marks the area depicted in Figure 2, in which the buoys drifted between December 20, 1991, and March 1, 1992. The trajectories all start in the top left corner of Figure 2, move first toward southeast, turn toward west, and finally continue eastward. The start and end of each trajectory are marked by the same symbol and the depths. The drifter in 17.5-m depth was taken up by a ship on January 27, 1992. For the remaining part until March 1, 1992, an average velocity, computed from the drifters in the levels $12.5 \mathrm{~m}$ and $22.5 \mathrm{~m}$, was used for this level. The drifter in $27.5 \mathrm{~m}$ was also lifted but was redeployed after a few hours (the straight line running north-south in the center of the area). During 2.5 months the buoys drifted less than $100 \mathrm{~km}$. The analysis was restricted to the period December 20,1991, to February 22, 1992 , because the uppermost drifter $(7.5 \mathrm{~m})$ became too separated from the remaining field by the end of February. Positions of the drifters, received 6-8 times per day, were interpolated by cubic splines to 1-hour intervals, from which the velocities were computed. In order to reduce tidal (12.4 hours) and inertial currents ( 14.2 hours), the data have been smoothed by computing running means over 13 hours. The velocities obtained are depicted in Figure 3. The envelope of the curves is a measure of the shear.

The mean separation of the buoys is $35 \mathrm{~km}$, and maximum separation is $90 \mathrm{~km}$. Although at any instant the velocities at

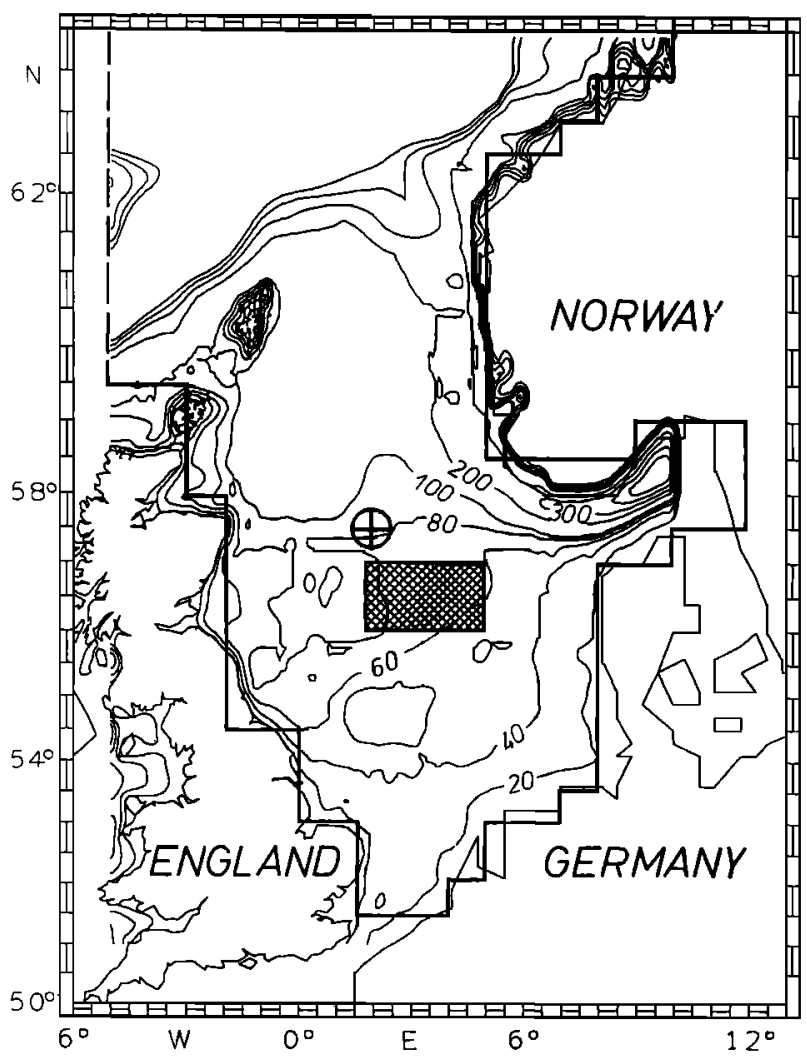

Figure 1. Area of buoy deployment in the North Sea (circle), area of trajectories shown in Figure 2 (shaded rectangle), and boundaries of the barotropic model.

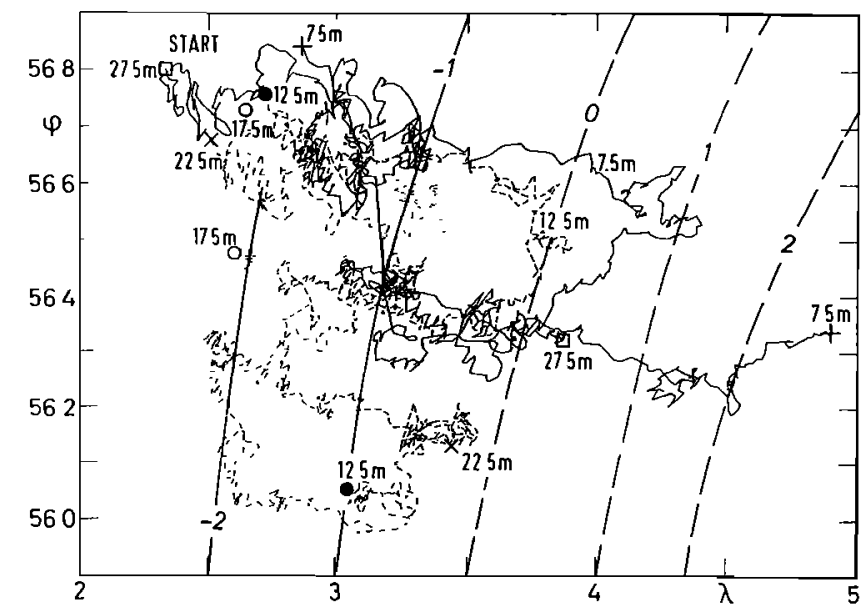

Figure 2. Trajectories of five drift buoys drogued at depths of $7.5 \mathrm{~m}, 12.5 \mathrm{~m}, \cdots, 27.5 \mathrm{~m}$. Symbols mark start and end. Dashed lines show sea level (in centimeters) due to westerly winds with $\tau^{x}=2 \mathrm{~g} /\left(\mathrm{cm} \mathrm{s}^{2}\right)$.

different levels are obtained at different locations, we consider these values as being representative for the shaded area in Figure 1. This conclusion is justified for the following reasons:

1. Storm surge models show that the sea level in the central North Sea varies smoothly over an area of $100 \mathrm{~km}$ by $100 \mathrm{~km}$. In Figure 2, for example, lines of constant sea level are shown due to westerly winds with $\tau^{x}=2 \mathrm{~g} /\left(\mathrm{cm} \mathrm{s}^{2}\right)$ according to model results. Within the accuracy of these models the sea level gradient can be considered to be constant over this area, which implies that the associated barotropic currents are constant too.

2. Moderate and strong wind fields, typically for winter conditions, extend over several hundred kilometers. Ekman currents must have similar scales if inertial currents are removed.

Therefore the computed drift velocities are treated as if they were obtained at the same position within the water column.

These drift velocities may be influenced by slippage. However, as the estimations in section 3 show, these errors are small compared to the observed velocities depicted in Figure 3.

In order to separate the Ekman currents from the barotropic ones we proceed as follows. Assuming linear dynamics, the currents are described by

$$
\begin{aligned}
& \frac{\partial u}{\partial t}-f v=-g \frac{\partial \zeta}{\partial x}+\frac{1}{\rho} \frac{\partial \tau^{x}}{\partial z}, \\
& \frac{\partial v}{\partial t}+f u=-g \frac{\partial \zeta}{\partial y}+\frac{1}{\rho} \frac{\partial \tau^{y}}{\partial z},
\end{aligned}
$$

where $\mathbf{v}=(u, v)$ is the sum of barotropic and Ekman velocity, $\zeta$ is sea level, $\tau=\left(\tau^{x}, \tau^{y}\right)$ is stress, and $f, g$, and $\rho$ are Coriolis parameter, gravity, and density, respectively.

The internal stress $\tau$ is decomposed into two parts: the Ekman stress $\tau_{E}$ due to the imposed wind stress and a "residual stress" $\tau_{R}$, which formally describes the errors in the computed sea level $\zeta$. Like $\zeta, \partial \tau_{R} / \partial z$ is assumed to be a function of time only within the shaded area of Figure 1 ; that is, $\tau_{R}$ varies linearly with depth. In order to compute the stresses from the observed velocities $u$ and $v$ according to (3), sea level inclinations must be known. 

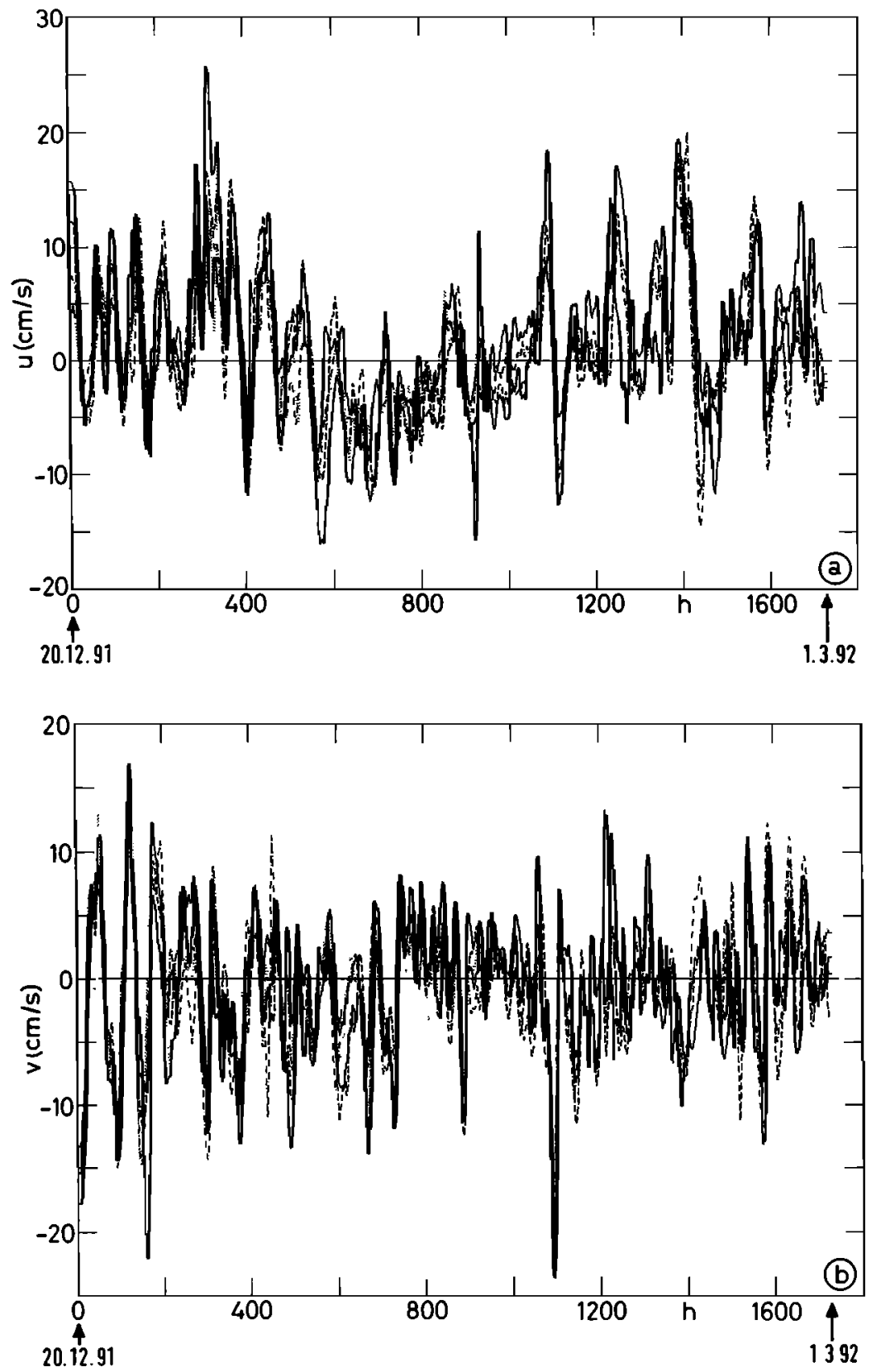

Figure 3. Velocities of the buoys during December 20, 1991 (20.12.91) to March 1, 1992 (3.1.92): (a) $u$ component, (b) $v$ component.

\subsection{Sea Level Inclination}

Sea level is computed by a numerical model of the vertically averaged equations (3) and the continuity equation. Driving forces are wind and air pressure from the weather forecast model of the German Meteorological Service. The model area is shown in Figure 1 by the straight lines; the grid interval is approximately $30 \mathrm{~km}$. The northern boundary at $64^{\circ} \mathrm{N}$ and the western boundary north of Scotland are treated as open boundaries, assuming geostrophic inflow and outflow.

Wind stress for the period December 20, 1991, to February 22, 1992, was computed according to the relations of Large and Pond [1981] from 6-hourly values of the wind velocity at $10 \mathrm{~m}$, taken from the European model of the German Meteorological Service. The stress components were spline interpolated to hourly values; they are depicted in Figure 4 for the $x$ and $y$ components. Extreme large values are reached during severe westerly storms in December and January, when stresses exceeded $8 \mathrm{~g} \mathrm{~cm}^{-1} \mathrm{~s}^{-2}$.

In Figure 5 we depict the resulting sea level inclinations $g \partial \zeta / \partial x$ and $g \partial \zeta / \partial y$ for the shaded area in Figure 1 as a function of time. These sea level inclinations show large quasiperiodic fluctuations at the beginning and at the end of the time series. These oscillations, having a typical period of about 40 hours, are rotary modes in the sea level variations which travel anticlockwise around the North Sea.

\subsection{Computation of Stresses}

Driven by the sea level inclination in the area (Figure 5), we compute the corresponding currents by solving (3) numerically, neglecting the stress terms. This yields a first guess of the 
barotropic currents (including errors due to errors in the sea level). These barotropic currents were subtracted from the observed ones (Figure 3 ); the resulting currents $\tilde{u}$ and $\tilde{v}$ were used to calculate the stresses according to

$$
\begin{gathered}
\frac{\partial \tilde{u}_{n-1 / 2}}{\partial t}-f \tilde{v}_{n-1 / 2}=\frac{\tau_{n-1}^{x}-\tau_{n}^{x}}{h_{n} \rho}, \\
\frac{\partial \tilde{v}_{n-1 / 2}}{\partial t}+f \tilde{u}_{n-1 / 2}=\frac{\tau_{n-1}^{y}-\tau_{n}^{y}}{h_{n} \rho}
\end{gathered}
$$

for the levels $n=1, \cdots, 6$, separated by $h_{n}=5 \mathrm{~m}$, except for the uppermost layer, which ranges from 0 to $10 \mathrm{~m}$. Here, $\tilde{\tau}_{0}$ is the wind stress. Further note that errors in the sea level inclination are portrayed as linearly increasing stresses in this analysis. This is the reason for introducing the "residual stress" $\tilde{\tau}_{R}$.

The next step is to extract that part of the stress which can be related to the local wind stress. In the classical Ekman spiral the relation between the stress at depth $z$ is related to the wind stress according to

$$
\begin{gathered}
\boldsymbol{\tau}(z)=D_{E}(z) \cdot \tau_{0}, \\
D_{E}(z)=e^{\gamma z},\left(\begin{array}{cc}
\cos \gamma z & -\sin \gamma z \\
\sin \gamma z & \cos \gamma z
\end{array}\right), \quad-\infty<z<0,
\end{gathered}
$$

where $\gamma=(f \rho / 2 \mu)^{1 / 2}, f$ is the Coriolis parameter, and $\mu$ is a constant viscosity. We call $D_{E}(z)$ the Ekman tensor.

Similarly to (5), we extract that part of the stress which can be directly related to the local wind stress. A tensor $D_{W}(z)$ is determined according to

$$
\tau=D_{w}(z) \cdot \tau_{0}
$$

by a least squares fit. Contrary to (5), $D_{W_{11}}=D_{W_{22}}$ and $D_{W_{12}}$ $=-D_{W_{21}}$ does not hold with sufficient accuracy.

Consistent with (5) we therefore define the Ekman tensor by the averages

$$
\begin{gathered}
D_{E_{11}}=\frac{D_{W_{11}}+D_{W_{22}}}{2}, \quad D_{E_{12}}=\frac{\mid D_{W_{12}|+| D_{W_{21}} \mid}^{2},}{2} \\
D_{E_{21}}=-D_{E_{12}}, \quad D_{E_{22}}=D_{E_{11}} .
\end{gathered}
$$

Then the linear Ekman problem is described by

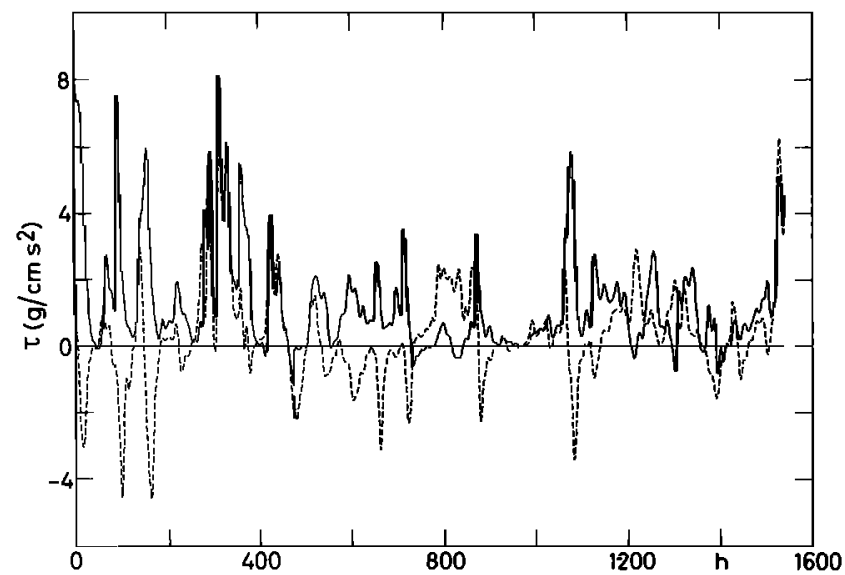

Figure 4. Wind stress $\tau^{x}$ (solid line) and $\tau^{y}$ (dashed line) for the period December 20, 1991, to February 22, 1992.
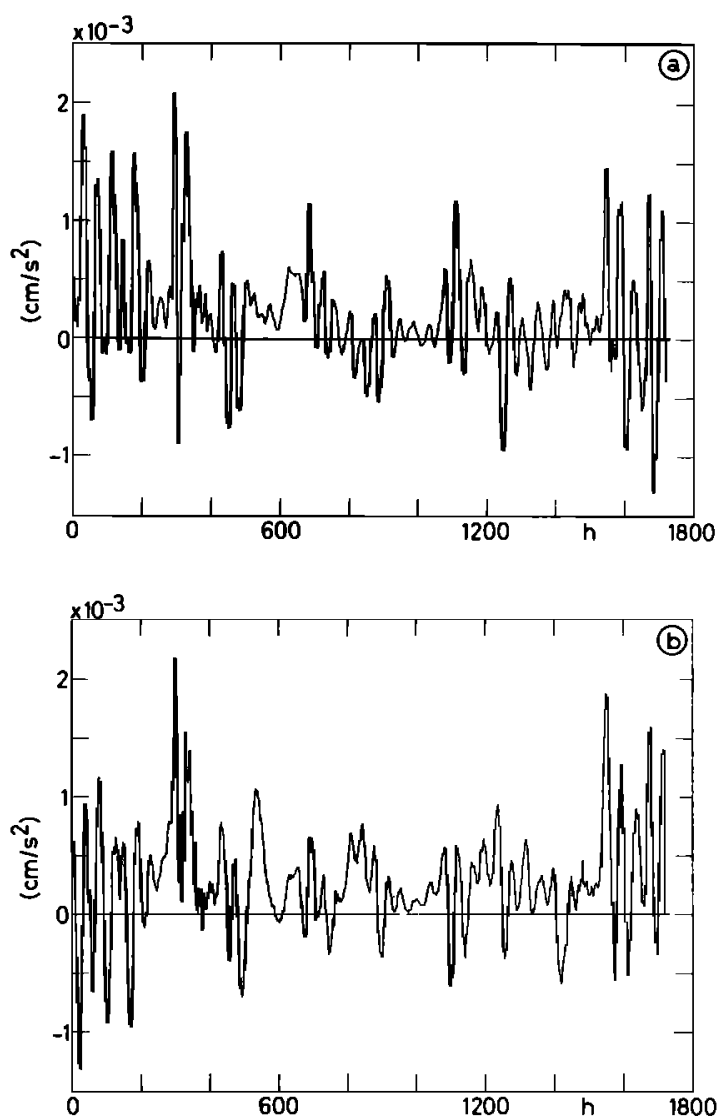

Figure 5. Computed sea level inclination (a) $g \zeta_{x}$ and (b) $g \zeta_{y}$ for the shaded area in Figure 1.

$$
\frac{\partial \mathbf{v}_{E}}{\partial t}+\mathbf{f} \times \mathbf{v}_{E}=\frac{d D_{E}}{d z} \cdot \tau_{0}
$$

where $\mathbf{v}_{E}$ are the Ekman currents and $D_{E}$ and $\tau_{0}$ are known from observations. Note that the wind acts as a body force within the depth range over which $D_{E}$ varies. The Ekman stress and the wind stress are related by

$$
\tau_{E}=D_{E} \cdot \tau_{0} \cdot
$$

The depth dependency of the Ekman tensor $D_{E}$ is depicted in Figure 6 (solid line) together with that which had been obtained for the period November-December 1991 [Krauss, 1993] (dashed lines). Compared with the previous results, the slope of the curves is the same for depths greater than $10 \mathrm{~m}$, but the curves are shifted slightly according to different values at $10-\mathrm{m}$ depth, resulting from the uppermost drifter. As its drogue extends from $3 \mathrm{~m}$ to $13 \mathrm{~m}$, we cannot exclude that its drift performance is influenced by breakers under severe storm conditions.

The elements $D_{E_{11}}$ decreased from 1 at the sea surface to about 0.5 at $30-\mathrm{m}$ depth, and $D_{E_{12}}$ increased from 0 to 0.7 ; the values at the sea surface stem from the boundary condition, $\tau_{E}=\tau_{0}$ for $z=0$. The vertical structure of $D_{E}$ rotates the Ekman stress uniformly from the wind direction at the surface toward the right.

The remaining residual stress, $\tau_{R}$, is determined by a least squares fit according to

$$
\tau_{R}(z, t)=(a+b z)\left(\tau-\tau_{E}\right),
$$




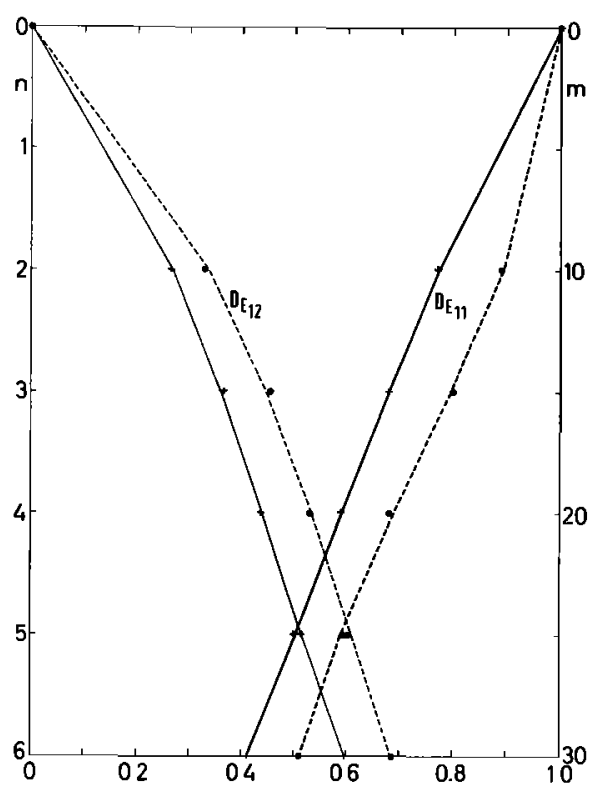

Figure 6. Elements of the Ekman tensor $D_{E}$ for the periods December-February (solid line) and November-December (dashed line). which then allows us to compute the barotropic currents, $\mathbf{v}_{b}$,

$$
\frac{\partial \mathbf{v}_{b}}{\partial t}+\mathbf{f} \times \mathbf{v}_{b}=-\nabla \zeta+\frac{\partial \tau_{R}}{\partial z}
$$

These barotropic currents are not required for the computation of the slippage $\mathbf{v}_{s}$, which is the speed of the system relative to $\mathbf{v}_{b}$. However, we use them for comparison.

In Figure 7 we depict the Ekman currents at $7.5-\mathrm{m}$ and 27.5-m depth (solid and dashed lines) together with the barotropic current. They have been computed according to

$$
\begin{array}{cc}
u_{B}=-\frac{1}{f}\left\{-g \zeta_{x}+\frac{d \tau_{R}^{x}}{d z}\right\} & v_{B}=\frac{1}{f}\left\{-g \zeta_{y}+\frac{d \tau_{R}^{y}}{d z}\right\} \\
\boldsymbol{v}_{E}=-\frac{1}{f \rho} \frac{d \tau_{E}^{x}}{d z} & u_{E}=\frac{1}{f \rho} \frac{d \tau_{E}^{y}}{d z}
\end{array}
$$

neglecting the time derivatives in the equations of motion, which are small compared with other terms.

Figure 7 illustrates why the determination of Ekman currents is a difficult task: Ekman currents are seldom stronger than the barotropic currents; thus most of the time, they are
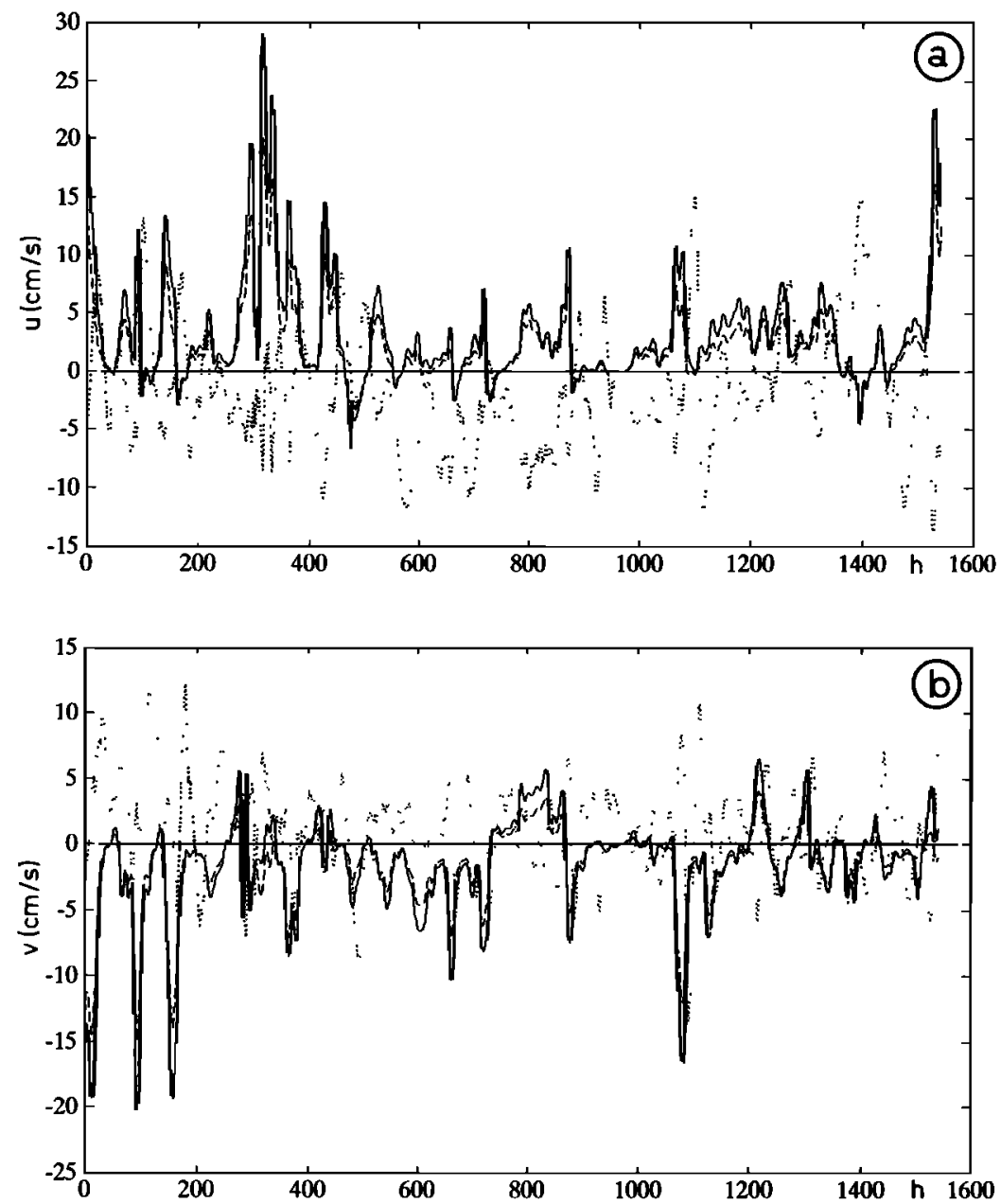

Figure 7. Ekman currents at 2.5-m (solid line) and 27.5-m depth (dashed line), for (a) $u$ component (east) and (b) $v$ component (north). Barotropic current is shown by dotted line. 

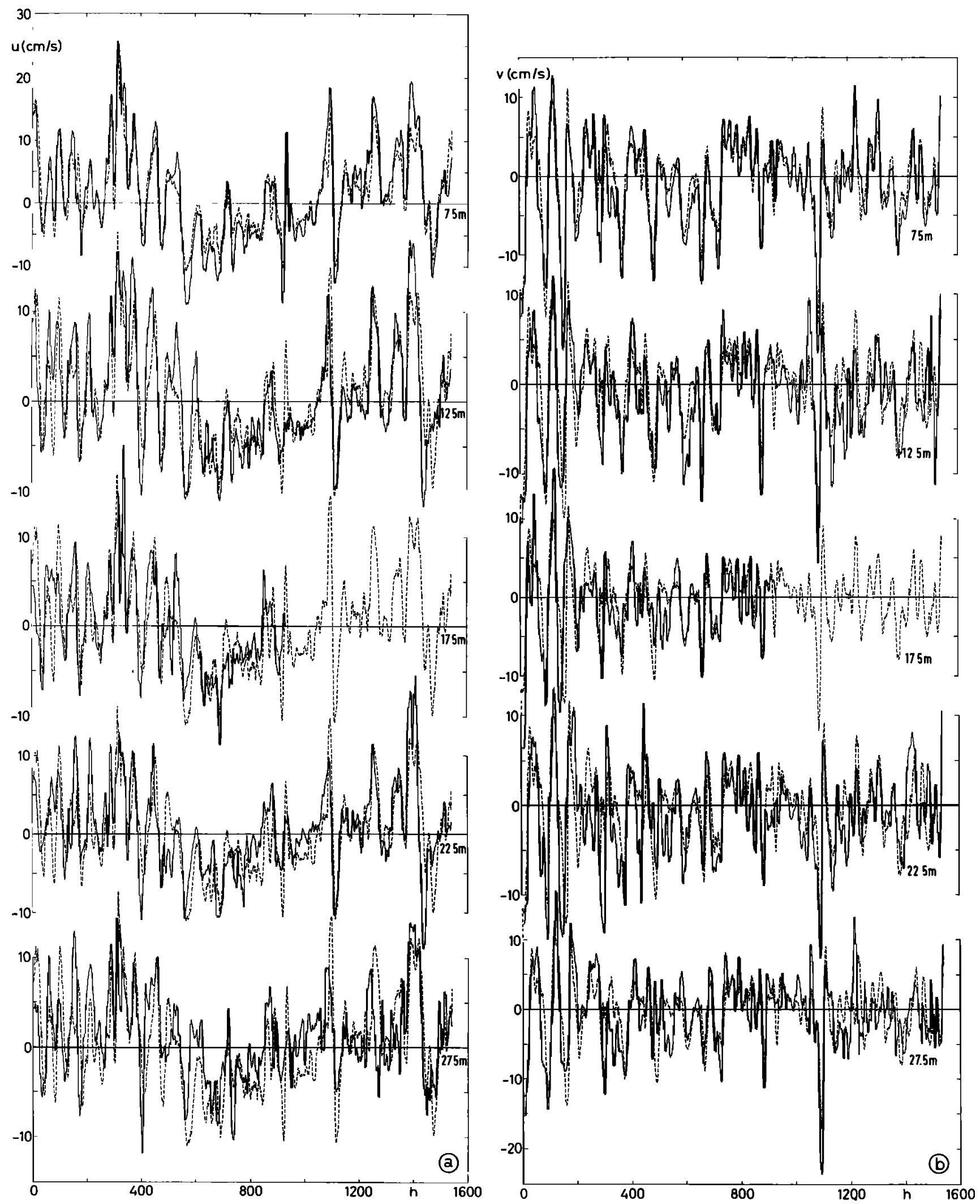

Figure 8. Observed currents (solid line) and numerically computed currents according to (12) (dashed line) in $7.5-\mathrm{m}, 12.5-\mathrm{m}, 17.5-\mathrm{m}, 22.5-\mathrm{m}$, and $27.5-\mathrm{m}$ depth, for (a) $u$ component and (b) $v$ component. 


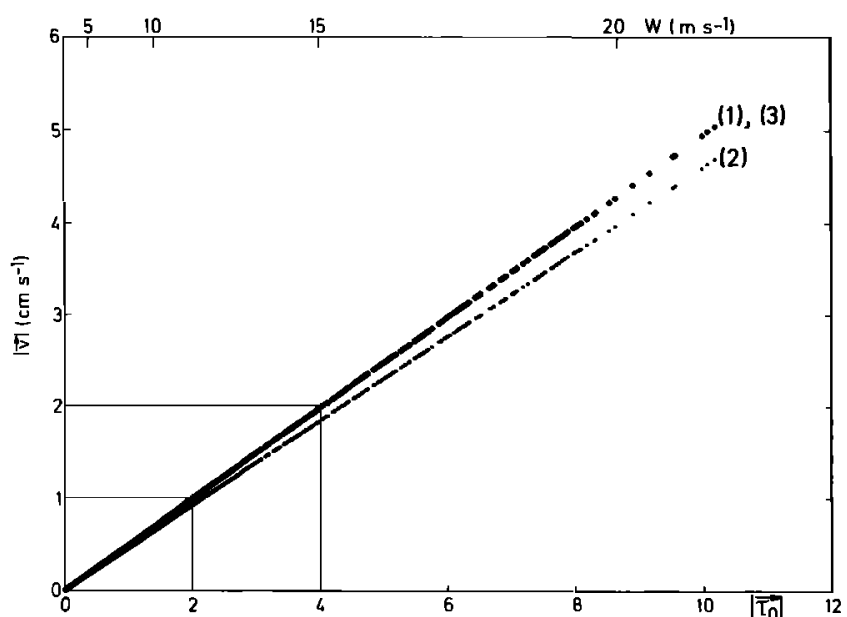

Figure 9. Slip velocity $\left|\mathbf{v}_{s}\right|$ as function of wind stress $\left|\boldsymbol{\tau}_{0}\right|$. Drogue at $100 \mathrm{~m}$ depth. Cases 1 and 2: Ekman currents are zero between $30 \mathrm{~m}$ and $100 \mathrm{~m}$. Case $1, c_{T}=c_{D}=c_{B}=1$; case $2, c_{T}=c_{D}=1.4 c_{B}=1$; case $3, c_{T}=c_{D}=c_{B}=1$ and linear decreasing currents to zero velocity at $100 \mathrm{~m}$ depth.

hidden in the total currents. Their superposition, $\mathbf{v}_{b}+\mathbf{v}_{E}$, is shown in Figure 8 together with the observed currents at each level. Within the upper $30 \mathrm{~m}$ of the water column the model is able to describe most of the current variability with respect to both amplitude and phase. We consider this to be an indication that the decomposition of the current field is realistic. However, no error bars can be assigned to these values.

\section{Performance of Deep-Drogued Drifters}

In the ideal case the drifter system should move with the barotropic current $\mathbf{v}_{b}$, which is the true current in drogue depth. However, if buoy and tether line give rise to a net drag force, the drogue must supply an equal and opposite force; that is, it does not follow the true current $\mathbf{v}_{b}$ but moves with a system velocity $\mathbf{v}_{\text {syst }}$. The difference, $v_{b}-v_{\mathrm{syst}}$, is the velocity of the drogue with respect to the surrounding water. It is called drogue slippage, $\mathbf{v}_{s}=\mathbf{v}_{b}-\mathbf{v}_{\text {syst }}$.

Given the wind stress $\tau_{0}$ and the Ekman currents at depths of $2.5 \mathrm{~m}, 7.5 \mathrm{~m}, \cdots, 27.5 \mathrm{~m}$, we compute the slippage of a drift buoy drogued at $100-\mathrm{m}$ depth, assuming quadratic laws for the drag on the system.

The balance of forces (equation (1)) given by quadratic drag laws (equation (2)) for each component of the system requires

$$
\begin{aligned}
& \rho_{W} \frac{c_{D}}{2} A_{D}\left|\mathbf{v}_{s}\right| \mathbf{v}_{s}=\rho_{W} \frac{c_{B}}{2} A_{B}\left|\mathbf{v}_{E}(0)-\mathbf{v}_{s}\right|\left(\mathbf{v}_{E}(0)-\mathbf{v}_{s}\right) \\
& +\rho_{W} \frac{c_{T}}{2} \frac{A_{T}}{H} \int_{0}^{H}\left|\mathbf{v}_{E}(z)-\mathbf{v}_{s}\right|\left(\mathbf{v}_{E}(z)-\mathbf{v}_{s}\right) d z+\frac{A_{B A}}{2} \tau_{0} .
\end{aligned}
$$

The left-hand term describes the force on the drogue due to slippage, and the right-hand terms are the forces on the submerged part of the surface buoy, the tether, and the buoy above surface, respectively. The symbols have the following meaning: $\rho_{W}$ is density of water; $c_{D}, c_{B}$, and $c_{T}$ are drag coefficients of drogue, buoy in water, and tether, respectively; $A_{D}, A_{B}$, and $A_{T}$ are the corresponding cross areas; $H$ is the length of the tether $(100 \mathrm{~m}) ; \mathbf{v}_{E}$ is the Ekman velocity, and $\mathbf{v}_{s}$ is slippage. The drag on the buoy in air was approximated by

$$
\rho_{L} \frac{c_{B A}}{2} A_{B A}|\mathbf{W}| \mathbf{W}=\frac{A_{B A}}{2} \tau_{0}
$$

where $\rho_{L}$ is density of air, $c_{B A}$ is drag coefficient of the buoy in air, $A_{B A}$ is the cross area of the buoy in air, $\mathbf{W}$ is wind velocity, and $\tau_{0}$ is wind stress. In this way we avoid the problem of reducing winds from $10 \mathrm{~m}$ height to winds directly at the sea surface. $A_{B A} \tau_{0}$ is the force exerted by the wind stress on the buoy. The factor $1 / 2$ has been chosen to take account for the frequent submergence of the buoy. As (14) is small compared with the remaining terms on the right-hand side of (13), this factor plays no essential role. The nonlinear equation (13) is solved iteratively for $\mathrm{v}_{s}$, starting with the balance between the left-hand side and the first term of the right-hand side, which are the dominant terms. An initial guess is obtained by assuming $\mathbf{v}_{s}=\alpha \mathbf{v}_{E}(\mathbf{0})$, which yields $\alpha=r^{1 / 2} /\left(1+r^{1 / 2}\right), r=$ $A_{B} / A_{D}$. The drag coefficient for the cylindrical buoy was assumed to be 1 . For tether and holey sock we assumed either 1 or 1.4 .

Figure 9 depicts the slippage $\left|\mathbf{v}_{s}\right|$ as a function of wind stress $\tau_{0}$. Cases 1 and 3 , based on $c_{T}=c_{B}=c_{D}=1$ but zero Ekman velocities below $30 \mathrm{~m}$ in case 1 and linear decreasing Ekman currents between $30 \mathrm{~m}$ and $100 \mathrm{~m}$ depth, in case 3, are indistinguishable. Case 2 is based on $c_{T}=c_{D}=1.4, c_{B}=1$. The resultant slippage is linearly related to the wind stress $\left|\tau_{0}\right|$ according to

Case 1

$$
\left|\mathbf{v}_{s}\right|=0.49\left|\tau_{0}\right|
$$

Case 2

$$
\left|\mathbf{v}_{s}\right|=0.46\left|\tau_{0}\right|
$$

This relationship is to be expected, because the Ekman currents at the surface are related to the wind stress according to $\left|\mathbf{v}_{E}\right|(0) \sim\left|\tau_{0}\right|[$ Krauss, 1993].

Thus for $\left|\mathbf{v}_{\mathrm{s}}\right| \ll\left|\mathbf{v}_{E}\right|$ the leading first term on the right-hand side of (13) is directly proportional to $\left|\boldsymbol{\tau}_{0}\right|$. For wind velocities less than $15 \mathrm{~m} / \mathrm{s}$ (Beaufort 7) slippage is smaller than $2 \mathrm{~cm} / \mathrm{s}$. Assuming that the wind condition of the winter 1991/1992 are typical for this season, in $89 \%$ of all cases (1540 hours), slippage is less than $2 \mathrm{~cm} / \mathrm{s}$. (Figure 10 and Table 1 ). The relative contributions from the submerged part of the buoy, tether, and

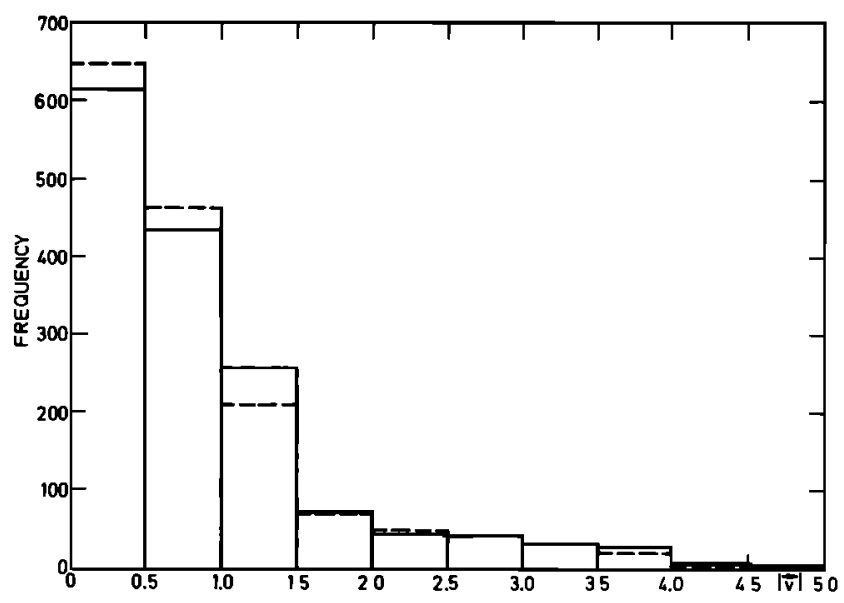

Figure 10. Histogram of slip velocity $\left|\mathbf{v}_{s}\right|$. Case 1, solid line; case 2 , dashed line. Drogue is at $100-\mathrm{m}$ depth. 
Table 1. Cumulative Relative Frequency of Slippage During December 1991 to February 1992 for Deep-Drogued Drifters

\begin{tabular}{ccc}
\hline \multirow{2}{*}{$\begin{array}{c}\text { Slippage } \\
|\mathrm{v},|, \\
\mathrm{cm} / \mathrm{s}\end{array}$} & \multicolumn{2}{c}{$\begin{array}{c}\text { Cumulative Relative } \\
\text { Frequency, \% }\end{array}$} \\
\cline { 2 - 3 } & Case 1 & Case 2 \\
\hline $0-0.5$ & 40 & 42 \\
$0.5-1.0$ & 68 & 72 \\
$1.0-1.5$ & 85 & 86 \\
$1.5-2.0$ & 89 & 90 \\
\hline
\end{tabular}

wind drag are $61 \%, 37 \%$ and $2 \%$, respectively, in case 1 . In case 2 the contributions are $51 \%, 45 \%$, and $4 \%$. Figure 11 depicts the barotropic velocities according to (12) before (solid line) and after (dashed line) correction for slippage. The rms barotropic velocity corrected for slippage is $5.0 \mathrm{~cm} / \mathrm{s}$ compared with the uncorrected value of $5.1 \mathrm{~cm} / \mathrm{s}$ for the $u$ component. The $v$ component is $3.5 \mathrm{~cm} / \mathrm{s}$ in both cases. Thus provided equation (13) is a good approximation to the real balance of forces, deep-drogued drifters measure geostrophic currents within error bars, which are acceptable.
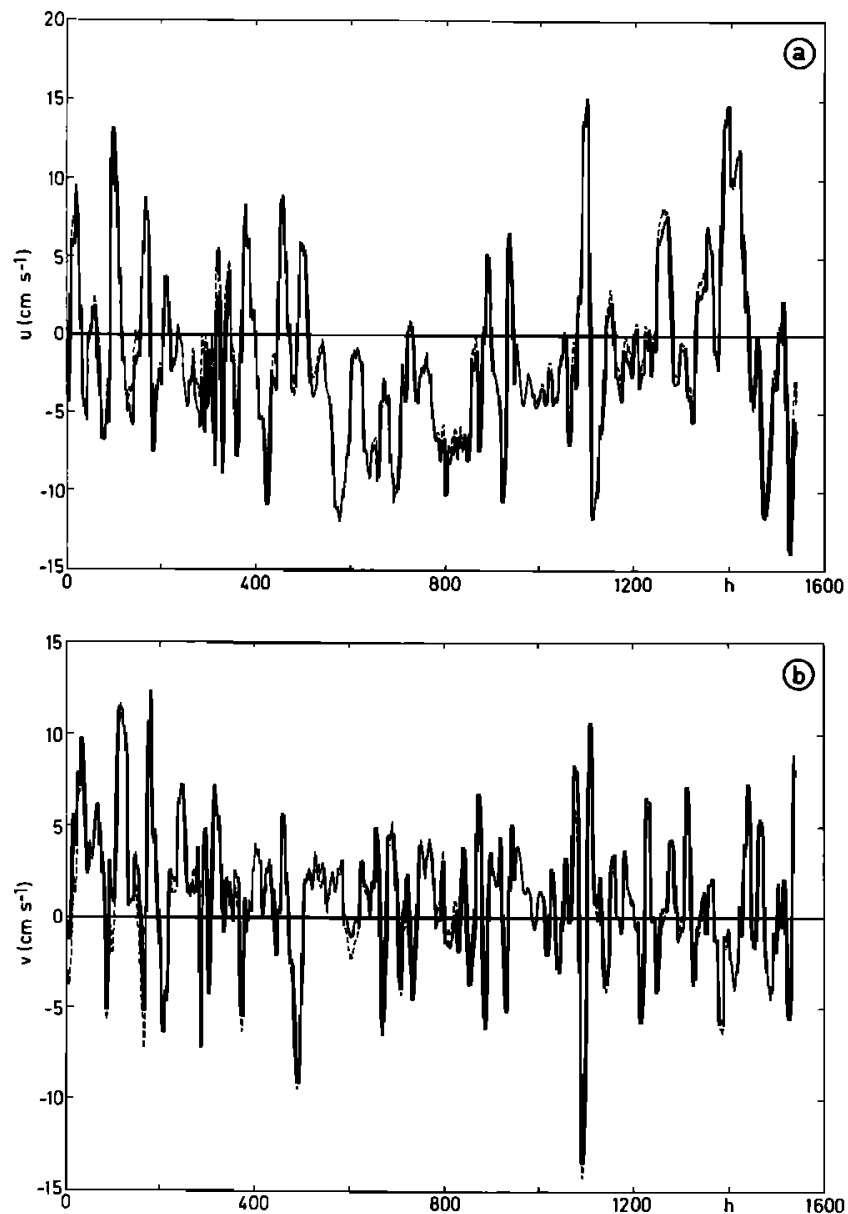

Figure 11. Barotropic currents according to (12) (solid line) and with correction for slippage (dashed line) for (a) $u$ component and (b) $v$ component.

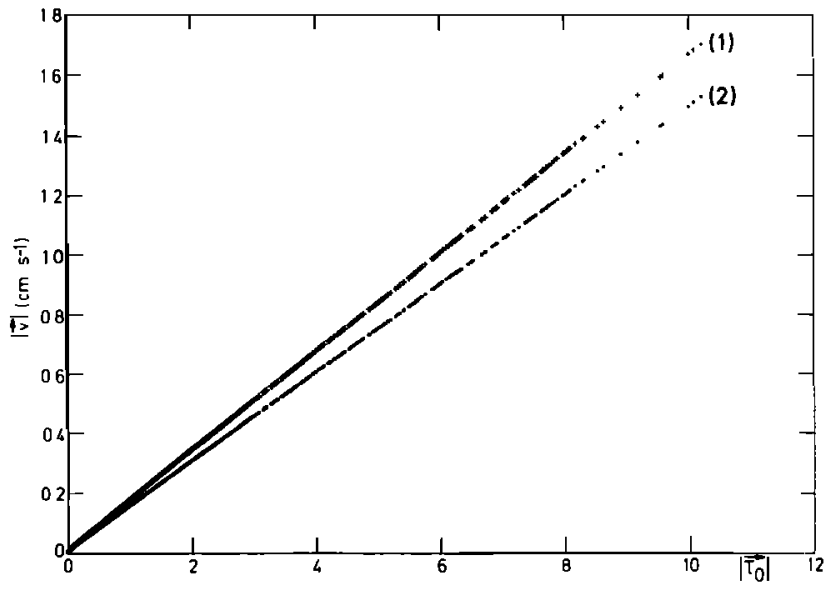

Figure 12. Slip velocity $\left|\mathbf{v}_{\mathrm{l}}\right|$ as a function of wind stress $\left|\boldsymbol{\tau}_{0}\right|$. Drogue is at $15-\mathrm{m}$ depth. Case $1, c_{T}=c_{D}=c_{B}=1$; case 2, $c_{T}=c_{D}=1.4 c_{B}=1$.

\section{Drifters in the Mixed Layer}

To compare these results with drifters drogued in the mixed layer, the same calculations have been done for a drogue extending from 10 - to $20-\mathrm{m}$ depth. Here the reference velocity of the system is the sum of barotropic and Ekman currents averaged over $10-20 \mathrm{~m}$. Figure 12 shows the slippage $\left|\mathbf{v}_{s}\right|$ as a function of the wind stress $\left|\tau_{0}\right|$. Case 1 is for $c_{T}=c_{B}=c_{D}=$ 1 , and case 2 is for $c_{T}=c_{D}=1.4, c_{B}=1$. As the influence of the tether is smaller, the drift performance is much better (three times). Slippage is given by

Case 1

$$
\left|\mathbf{v}_{s}\right|=0.17\left|\tau_{0}\right|
$$

Case 2

$$
\left|\mathbf{v}_{s}\right|=0.15\left|\tau_{0}\right|
$$

and remains less than $2 \mathrm{~cm} / \mathrm{s}$ for all wind conditions. The frequency distribution for this case is shown in Figure 13, and cumulative relative frequencies are listed in Table 2.

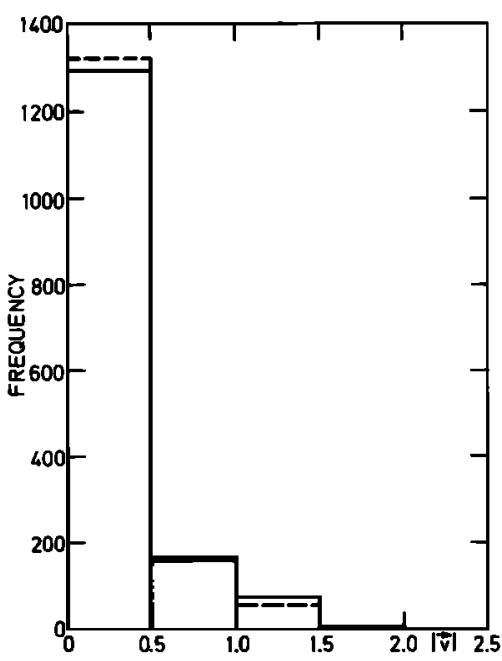

Figure 13. Histogram of slip velocity $\left|\mathbf{v}_{s}\right|$. Case 1, solid line; case 2 , dashed line. Drogue is at $15-\mathrm{m}$ depth. 
Table 2. Cumulative Relative Frequency of Slippage During December 1991 to February 1992 for Mixed Layer Drifters

\begin{tabular}{ccc} 
Slippage & \multicolumn{2}{c}{$\begin{array}{c}\text { Cumulative Relative } \\
\text { Frequency, \% }\end{array}$} \\
\cline { 2 - 3 }$\left|\mathbf{v}_{s}\right|$, & Case 1 & Case 2 \\
$\mathrm{cm} / \mathrm{s}$ & 84 & 86 \\
$0-0.5$ & 95 & 96 \\
$0.5-1.0$ & 99.6 & 99.9 \\
$1.0-1.5$ & 100 & 100 \\
$1.5-2.0$ & & \\
\hline
\end{tabular}

The advantage of a better performance of the mixed layer drifter is more than compensated by the fact that the measured current is a mixture of Ekman current and barotropic current. Figure 14 depicts the measured averaged current (barotropic plus Ekman) for the layer $10-20 \mathrm{~m}$ (solid line), the averaged Ekman current for this layer (dashed line), and the barotropic current (dotted line). In the case of the North Sea experiment, it was possible to separate the Ekman currents from the barotropic ones, because drifters were drogued at different depths, allowing analysis of the vertical shear in the Ekman currents. If drift velocities are available only at one level and stratification
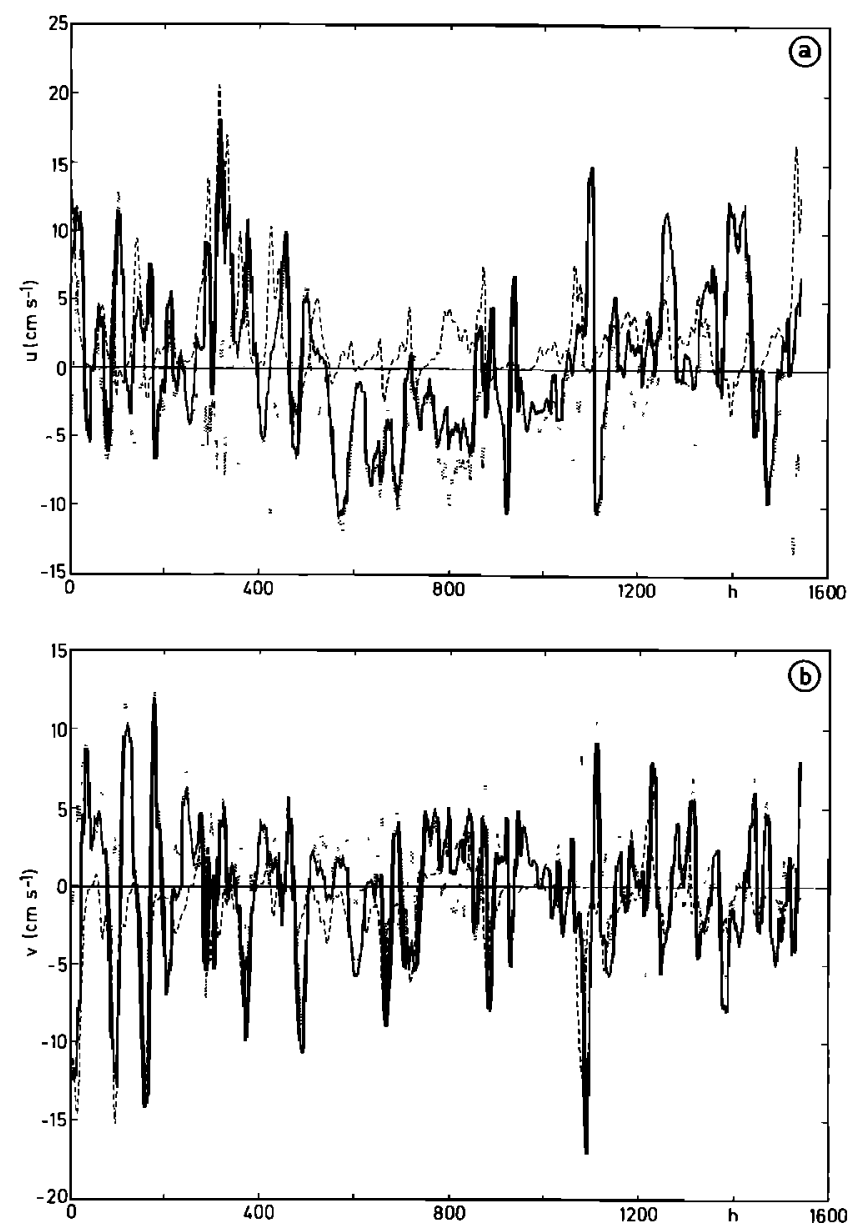

Figure 14. Total (barotropic and Ekman) current averaged over the interval $10-20 \mathrm{~m}$ (solid line), Ekman current averaged over the interval $10-20 \mathrm{~m}$ (dashed line), and barotropic current (dotted line) for (a) $u$ component and (b) $v$ component.
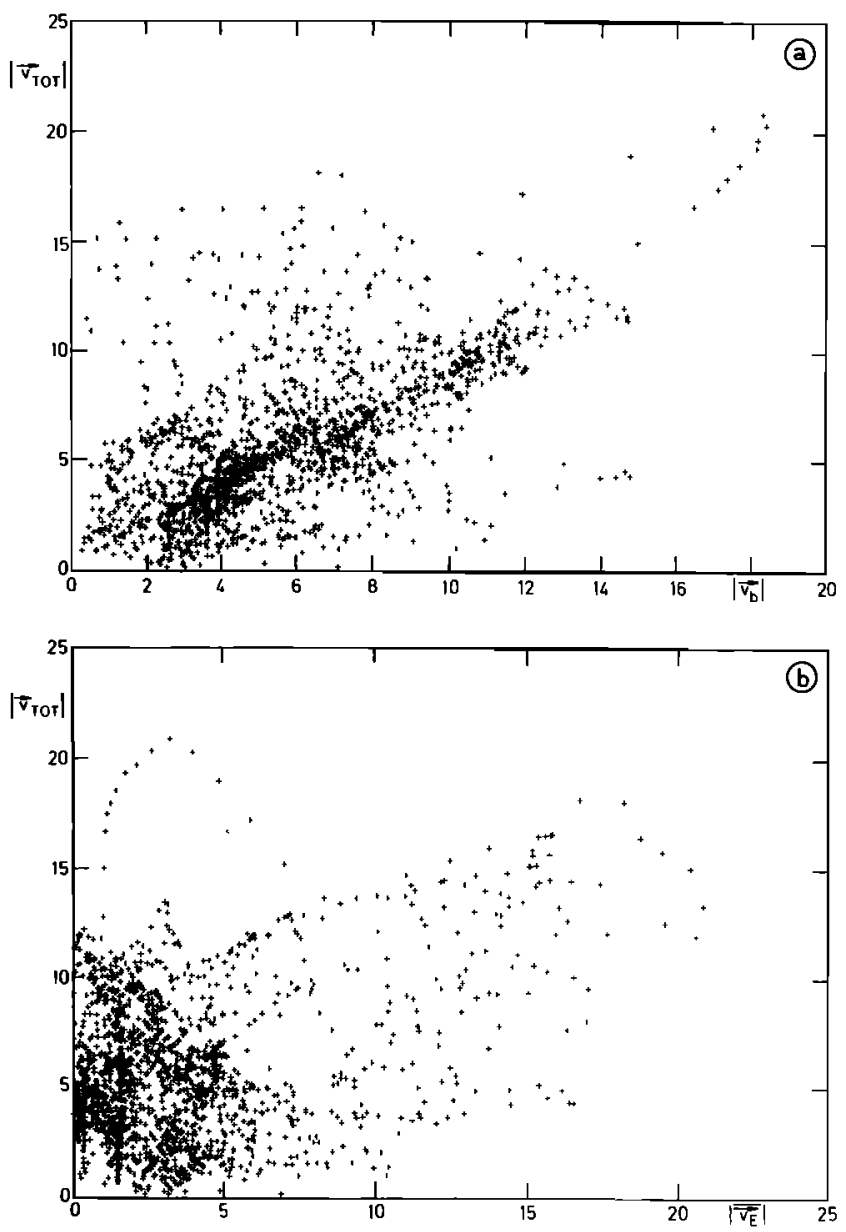

Figure 15. Total current (as in Figure 14) versus (a) barotropic current and (b) Ekman current.

influences the vertical distribution of the Ekman currents, it seems hopeless to carry out such a separation. It would require decomposing the solid line in Figure 14 into the dashed and dotted ones. As both the barotropic and the Ekman currents are highly variable in time, as is shown in Figure 7, the averaged total current for the layer $10-20 \mathrm{~m}$ shows a relation neither to the barotropic nor to the Ekman currents. This is shown in Figure 15 by scatter diagrams.

On the basis of these results the question may be raised whether the usage of a standard drogue depth on oceanwide drift experiments is adequate. Generally, mixed layer drifter observations are intended to address scientific questions different from those addressed by deep-drogued drifters. In the latter case the drifters are aimed to show as little influence from wind-produced surface currents as possible. The $100-\mathrm{m}$ drogue depth is a compromise between eliminating the action of direct drift currents on the drogue and minimizing the drag on the tether. Whether this aim is reached in some areas during winter conditions remains an open question.

The better performance of mixed layer drifter regarding slippage is surely an advantage if the near-surface current field is to be studied. These drifters provide valuable data needed to validate models of the mixed layer and the response of the surface layers to variable atmospheric conditions. However, to obtain insight into the geostrophic current field, the slightly larger slippage of deep-drogued drifters can be tolerated. 


\section{Conclusions}

Satellite-tracked drifters provide the only direct method for investigating the currents in the upper ocean on all scales. However, their calibration is a very difficult task. Direct measurements of slippage have been performed only under light winds and may not be representative for middle and high latitudes under typical winter conditions. Under light winds the quadratic drag law has proven to be a good approximation of the forces acting on the system [Geyer, 1989]. Forces due to wave action in heavy sea are generally unknown. It also remains unknown whether mixed layer drifters are influenced more strongly under these conditions because of the direct exposure of their drogue to the wave action. This may result in a complicated shape of the tether and in different buoy-drogue dynamics. The main deficiency at present is the lack of instrumented test data for verifying the estimated errors. However, one has to bear in mind that most instruments fail close to the sea surface in fully developed wind-driven seas at high wind velocities.

On the basis of a data set from the North Sea, in which Ekman currents and barotropic currents have been separated, the influence of the Ekman currents on deep-drogued drifters has been studied. During a 2-month period in winter 19911992 all wind velocities, typical for middle and high latitudes, occurred. Thus a realistic estimate of Ekman currents could be used in this analysis.

In $90 \%$ of all cases the computed slippage was less than 2 $\mathrm{cm} / \mathrm{s}$. This number should improve during the remaining seasons. The balance of forces does not include a direct wave action on the system. Furthermore, drag coefficients are known only for steady flow conditions. Comparison between altimeter-derived geostrophic currents and those from drifters in the North Atlantic [Willebrand et al., 1990] gave 7\% higher values for the drifter velocities, which can be real owing to the different scales measured by both methods. On the other hand, it indicates that the values derived from the balance of forces according to (13) seem to be realistic. Thus deep-drogued drifters can be used as a reliable device to measure weakly baroclinic geostrophic currents in the ocean. Instead of the barotropic currents related to storm surges, which are used in this article as a realistic signal to be measured, in the deep ocean we have the baroclinic currents as a dominant signal. As the first mode generally dominates these currents, they vary little within the upper $100 \mathrm{~m}$. Their time variability is comparable to that in Figure 7 due to eddies and meanders.

In most cases, trajectories of the drifters are only used to derive the velocities along the drift. To improve a data set, velocities obtained during periods of severe storms could be discarded. This procedure may be recommended for areas of low mean kinetic energy such as the eastern North Atlantic Ocean.

To obtain worldwide uniform data sets, standard drogue depths are an essential prerequisite. With respect to mixed layer drifters this standardization is already reached. Regarding deep-drogued drifters the $100-\mathrm{m}$ level seems to be a good compromise. Except in the tropical ocean the first baroclinic mode generally dominates the vertical structure of the large ocean currents. This mode is approximately constant above the main thermocline. Thus drifters that follow the flow in $100-\mathrm{m}$ depth yield representative geostrophic currents of the upper $300-400 \mathrm{~m}$ in most areas in midlatitudes.

\section{References}

Beckmann, A., C. W. Böning, B. Brügge, and D. Stammer, On the generation and role of eddy variability in the central North Atlantic, J. Geophys. Res., 99(C10), 20,381-20,391, 1994.

Bitterman, D. S., and D. V. Hansen, The design of a low cost tropical drifter buoy, paper presented at Marine Data Systems International Symposium, Mar. Technol. Soc., New Orleans, La., April 30 to May 2, 1986.

Bitterman, D., P. Niiler, Y. Aoustin, and A. du Chaffaut, Drift buoy intercomparison test results, NOAA Data Rep. ERL AOML-17, pp. 1-52, Dep. of Commer., Washington, D. C., 1990.

Booth, D. A., Horizontal dispersion in the northeast Atlantic, Deep Sea Res., 35, 1937-1951, 1988.

Brügge, B., Near-surface mean circulation and kinetic energy in the central North Atlantic from drifter data, J. Geophys. Res., 95(C10), 20,543-20,554, 1995.

Colin de Verdière, A., Lagrangian eddy statistics from surface drifters in the eastern North Atlantic, J. Mar. Res., 41, 375-398, 1983.

Davis, R. E., Lagrangian ocean studies, Annu. Rev. Fluid Mech., 23, 43-64, 1991.

Emery, W. J., T. C. Royer, and R. W. Reynolds, The anomalous tracks of North Pacific drifting buoys 1981 to 1983, Deep Sea Res., 32, 315-347, 1985.

Geyer, W. R., Field calibration of mixed-layer drifters, J. Atmos. Ocean Technol., 6, 333-342, 1989.

Hansen, D., and C. A. Paul, Vertical motion in the eastern equatorial Pacific inferred from drifting buoys, Oceanol. Acta, Symp. Proc., 27-32, 1987.

Krauss, W., Ekman drift in homogeneous water, J. Geophys. Res., 98(C11), 20,187-20,209, 1993.

Krauss, W., J. Dengg, and H.-H. Hinrichsen, The response of drifting buoys to currents and wind, J. Geophys. Res., 94(C3), 3201-3210, 1989.

Krauss, W., J. Dengg, and H.-H. Hinrichsen, Reply to comment by P.-M. Poulain and P. P. Niiler on "The response of drifting buoys to currents and wind," J. Geophys. Res., 95(C1), 801-803, 1990a.

Krauss, W., R. Döscher, A. Lehmann, and T. Viehoff, On eddy scales in the eastern and northern North Atlantic Ocean as a function of latitude, J. Geophys. Res., 95, 18,049-18,056, 1990 b.

Large, W. G., and S. Pond, Open ocean momentum flux measurements in moderate to strong winds, J. Phys. Oceanogr., 11, 324-336, 1981.

McNally, G. J., Satellite-tracked drift buoy observations of the nearsurface flow in the eastern mid-latitude North Pacific, J. Geophys. Res., 86(C9), 8022-8030, 1981.

Niiler, P., R. Davis, and H. J. White, Water-following characteristics of a mixed layer drifter, Deep Sea Res., 34, 1867-1881, 1987.

Price, J. F., R. A. Weller, and R. Pinkel, Diurnal cycling: Observations and models of the upper ocean response to diurnal heating, cooling, and wind mixing, J. Geophys. Res., 91, 8411-8427, 1986.

Price, J. F., R. A. Weller, and R. R. Schudlich, Wind-driven ocean currents and Ekman transport, Science, 238, 1534-1538, 1987.

Schäfer, H., and W. Krauss, Eddy statistics in the South Atlantic as derived from drifters drogued at $100 \mathrm{~m}, J$. Mar. Res., 53, 403-431, 1995.

Stammer, D., and C. W. Böning, Mesoscale variability in the Atlantic Ocean from Geosat altimetry and WOCE high-resolution numerical modelling, J. Phys. Oceanogr., 22, 732-752, 1992.

Thomson, R., P. LeBlond, and W. J. Emery, Analysis of deep-drogued satellite-tracked drifter measurements in the northeast Pacific, Atmos. Ocean, 28(4), 409-443, 1990.

Willebrand, J., R. H. Kàse, D. Stammer, H.-H. Hinrichsen, and W. Krauss, Verification of Geosat sea surface topography in the Gulf Stream extension wich surface drifting buoys and hydrographic measurements, J. Geophys. Res., 95(C3), 3007-3014, 1990.

W. Krauss, Institut für Meereskunde, Universität Kiel, Dústernbrooker Weg 20, D-24105 Kiel, Federal Republic of Germany. (e-mail: wkrauss@ifm.uni-kiel.d400.de)

(Received August 7, 1994; revised June 16, 1995; accepted July 31, 1995.) 